Research Article

\title{
Assessing land use change in the context of climate change and proposing solutions: Case study in Gia Lai province, Vietnam
}

\author{
Nguyen Ninh Hai ${ }^{1}$, Nguyen Tuan Anh ${ }^{1}$, Nguyen Minh Ky ${ }^{1 *}$, Bach Quang Dung*, \\ Nguyen Thi Nhu Huong ${ }^{3}$, Nguyen Hoang Dieu Minh ${ }^{1}$, Nguyen Thi Ly ${ }^{1}$ \\ ${ }^{1}$ Nong Lam University of Ho Chi Minh City, Gia Lai campus, Tran Nhat Duat Street, \\ Dien Phu Ward, Pleiku City, Gia Lai Province, Vietnam. \\ ${ }^{2}$ Viet Nam Meteorological and Hydrometeorological Administration, Ha Noi, Vietnam. \\ ${ }^{3}$ Pleiku High School, Gia Lai Province, Vietnam. \\ *Correspondence: nmky@hcmuaf.edu.vn; dungmmu05@gmail.com; \\ Tel.: +84-384321415. \\ Received: 10 March 2021; Accepted: 15 April 2021; Published: 25 April 2021
}

\begin{abstract}
The study presents the results of the assessment of land use change in the period 2014-2019 in Chu Pah district, Gia Lai province and proposed solutions. The research used the methods including data collection, spatial analysis, stakeholder and expert analysis. Remote sensing imagery (Google Earth) is employed to interpret, and the conducted field survey to verify in 14 communes and towns in order to create the current map of land use with high accuracy. For instance, the group of agricultural land changes the largest with the conversion of annual crop land into perennial crops. The area of residential land increases due to the increasing demand of residential land and the population growth. In addition, the group of unused land decreased relatively high mainly to meet the needs of cultivation and afforestation. The negative impacts of climate change also contribute to change the purpose and status of land resources in Chu Pah district. The results are meaningful in providing database for establishing land use status quo map and making decisions on sustainable socio-economic development.
\end{abstract}

Keywords: Land use change; Land management; Climate change; Google Earth; Remote sensing.

\section{Introduction}

Studying land use change is to clarify changes and use land resources effectively in specific areas using modern technologies such as remote sensing and geographic information systems [1-3]. Many studies showed that land cover change is an important factor in environmental change. Therefore, research on land use change is considered by scientists and managers to analyze the causes. In fact, there are many methods of determining the process of land use changes such as applying experimental models to assess changes in land cover by remote sensing [3-6]. However, this approach is unsuccessful in explaining human behavior leading to land use change. According to another approach, spatial modeling can be used to determine the process of land use changes based on the Google Earth satellite images [7-9]. Advantages of using Google Earth can provide high spatial resolution satellite imagery. Google Earth provides images at different times and is therefore very useful in the process of urban planning development and in determining land use and land cover changes. High resolution Google Earth satellite imagery can observe visual objects such as residential areas, construction works, transport systems, water surface, etc. to integrate into GIS to create the current land use map [9]. These changes will then be used to assess impacts related to 
policy and other factors. In addition, statistical analysis method is a useful tool due to the ability to test hypotheses, rank factors, test hypothesis rigor. However, the process requires a combination of spatial, temporal and analytical data, so there are still obstacles and challenges to achieving the accuracy results [10].

Chu Pah district is an important gateway in the northern economic corridor of Gia Lai province and Pleiku city. Chu Pah is located in an important position and has exchange advantages to promote local socio-economic development [11]. Meanwhile, the process of economic development and urbanization has caused many problems in the management and use of land resources such as degradation, inappropriate use of resources, and land disputes [12]. According to the scenarios of climate change and sea level rise for Vietnam, compared with the period of time 1980-1999, the average temperature will be increased around 2 to $3^{\circ} \mathrm{C}$ at the end of this century [13]. Also, with the current negative impacts of climate change in the Central Highlands region is significant. Land use change is a research process related to the way people use land. It alters the availability of various resources including vegetation, soil, and water. Water resources management could be affected by land-use change such as the amount of evapotranspiration, groundwater infiltration and overland runoff [14]. In addition, climate patterns, natural hazards also could be affected negatively on a global and local scale [15]. Climate change is the change of the climate system such as hydrosphere, biosphere and lithosphere by natural and artificial causes. According to research [16] showed that the impacts of climate change have changed agricultural activities. Similarly, the research showed that many areas of Gia Lai province are affected by variations in temperature, precipitation, and extreme weather events such as droughts and floods. In agriculture, there should be many synchronous solutions, in which the change of crop structure needs to be suitable with the weather conditions of the area [17]. There is an urgent problem to be addressed in the state management of land resources.

Therefore, it is important to assess land use change and propose solutions for effective land use and management, providing detailed and accurate information for policy making. At the same time, the results also support the management of rational and efficient use of land resources, meeting the use demands of economic, cultural and security and defense sectors.

\section{Methods}

\subsection{Study area}

Located in the north of Gia Lai province, Chu Pah district has a natural area of 97,457.68 ha, bordering Kon Tum province in the North; Dak Doa district in the East; Ia Grai district in the west; Pleiku city and Ia Grai district in the south. Climate characteristics of Chu Pah district are characterized by the Central Highlands, the humid tropical climate of the south Vietnamese monsoon, there is a distinct difference and contrast between the two seasons. The dry season is from November to April each year with low rainfall, and the rainy season is hot, humid, and rainy, from May to October.

\subsection{Methods}

\subsubsection{Secondary data collection}

This method is used to collect data and documents including topographic and hydrological maps [18]; Report on the results of the review and adjustment of 3 forest types in Gia Lai province to 2025 and a vision to 2030 and other relevant documents on administrative boundaries [11]. 


\subsubsection{Mapping and spatial analysis}

To analyze and determine the spatial change of land use categories in the period 20142019, the study used MicroStation V8i software to establish and edit maps based on Google Earth satellite images (Landsat 8, 30x30 m). In addition, the area of land units are calculated by automatic topology using TK Desktop software Version 3.6.

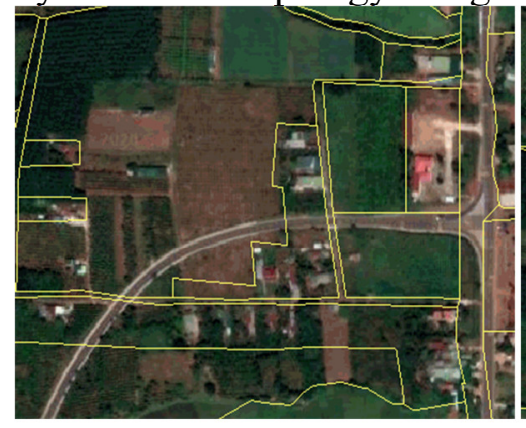

2014

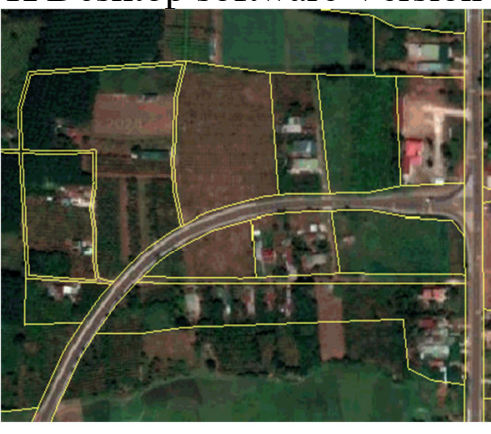

2019

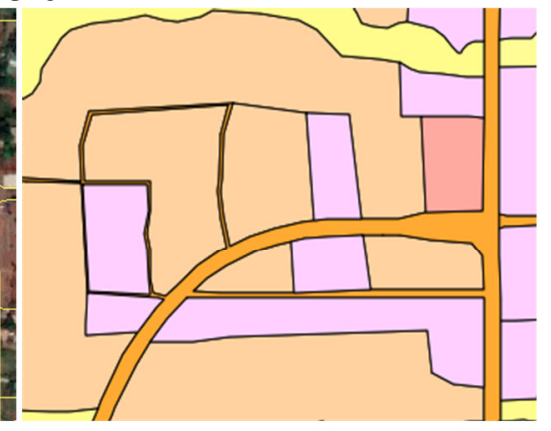

The status quo map 2019

Figure 1. Mapping and status quo map.

For Google Earth satellite image data (*.TIF), the study used as of 2014 and 2019 (Google Earth Engine: A planetary-scale platform for Earth science data \& analysis. URL: https://earthengine.google.com), then converted the WGS84 satellite image coordinates to the VN2000 standard map coordinate system. This study used the coordinate transformation between world geodetic system (WGS84) and Vietnam geodetic system (VN2000) for calculating process [19]. The formula converts the pixel's X-coordinate to the longitude and the y-coordinate of a pixel to latitude, using equations (1) and (2), respectively.

$$
\left.\mathrm{x}=\left[2^{\mathrm{z}+7}\left(1+\frac{\text { longitude }}{180}\right)\right](1) ; y=2^{z+7}\left(1-\frac{1}{2 \pi} \log \left(\frac{1+\sin \left(\text { latitude } \frac{\pi}{180}\right)}{1-\sin \left(\text { latitude } \frac{\pi}{180}\right.}\right)\right)\right]
$$

In which, $\mathrm{x}$ is pixel's $\mathrm{x}$-coordinate to the longitude; $\mathrm{y}$ is the $\mathrm{y}$-coordinate of a pixel to latitude; and $\mathrm{z}$ is ellipsoidal height. After downloading and merging Google Earth images with Universals Map Downloader version 9.10 software. Google Earth images will be referenced to the MicroStation V8i software using manual image interpretation method based on the satellite image interpretation keypad. Specifically, in order to perform the satellite imagery interpretation process, the study establishes image interpretation patterns and is described in Table 1. These image interpretation patterns are consistent and followed as land management standards.

Table 1. Google Earth imagery interpretation.

\begin{tabular}{|c|c|c|c|c|c|}
\hline Objective & Pattern & Color & Size & Shape & Topographic \\
\hline $\begin{array}{l}\text { Perennial } \\
\text { crops }\end{array}$ & & $\begin{array}{l}\text { Dark blue, } \\
\text { black }\end{array}$ & Large & $\begin{array}{l}\text { Large, very } \\
\text { large cluster }\end{array}$ & Flat or sloping \\
\hline $\begin{array}{l}\text { Stream and } \\
\text { river }\end{array}$ & & $\begin{array}{l}\text { Bright, milky } \\
\text { white }\end{array}$ & Unstable & Meandering & Lowlands, valleys \\
\hline $\begin{array}{l}\text { Residential } \\
\text { land }\end{array}$ & & Green gray & Small & $\begin{array}{l}\text { Rectangular, } \\
\text { square }\end{array}$ & $\begin{array}{c}\text { Flat land, small } \\
\text { slope }\end{array}$ \\
\hline $\begin{array}{l}\text { Aquaculture } \\
\text { land }\end{array}$ & & Blue & Small & $\begin{array}{l}\text { Rectangular, } \\
\text { square }\end{array}$ & Flat, sunken \\
\hline Paddy land & & Green & Unstable & $\begin{array}{l}\text { Polygons, } \\
\text { plots }\end{array}$ & $\begin{array}{l}\text { Low-lying, } \\
\text { riverine }\end{array}$ \\
\hline
\end{tabular}


VN J. Hydrometeorol. 2021, 7, 20-31; doi:10.36335/VNJHM.2021(7).20-31

\begin{tabular}{|c|c|c|c|c|c|}
\hline Objective & Pattern & Color & Size & Shape & Topographic \\
\hline Transport land & & Greyish & Unstable & Linear form & Flat, sloping land \\
\hline Forest land & & Black blue & Very large & $\begin{array}{l}\text { Very large } \\
\text { cluster }\end{array}$ & Hilly \\
\hline Water surface & & Dark green & Medium, large & $\begin{array}{l}\text { Cluster, round } \\
\text { shape }\end{array}$ & Lowlands, lower \\
\hline Unused land & & Red gray & Medium, large & $\begin{array}{l}\text { Large, very } \\
\text { large cluster }\end{array}$ & Hilly, large slope \\
\hline
\end{tabular}

\subsubsection{Accuracy assessment}

The method of accuracy assessment aims to confirm the accuracy and acceptance of the satellite image interpretation [20-21]. In order to assess reliability, the study conducted field survey and recorded GPS location, and create a matrice to calculate Overall Accuracy and Kappa (K), which is to verify the results of satellite image interpretation [21-22]. Kappa can be used in accuracy assessment and determine the values of error matrix. Kappa is computed as equation (3).

$$
\mathrm{K}=\frac{\mathrm{N} \sum_{\mathrm{i}=1}^{\mathrm{r}} \mathrm{x}_{\mathrm{ii}}-\sum_{\mathrm{j}=1}^{\mathrm{r}}\left(\mathrm{x}_{\mathrm{i}+} * \mathrm{x}_{+\mathrm{i}}\right)}{\mathrm{N}^{2}-\sum_{\mathrm{j}=1}^{\mathrm{r}}\left(\mathrm{x}_{\mathrm{ii}} * \mathrm{x}_{+\mathrm{i}}\right)}
$$

where $r$ is the number of rows of the matrix; $x_{i i}$ is the number of observations of row and column $\mathrm{i} ; \mathrm{x}_{\mathrm{i}^{+}}$and $\mathrm{x}_{+\mathrm{i}}$ are respectively the marginal totals of row and column $\mathrm{i}$; and $\mathrm{N}$ is the total number of observations [22]. In this study, the field survey took 123 random samples of target groups (Figure 2) including perennial crop land (15 samples), stream and river land (9 samples), residential land (9 samples), aquaculture land (12 samples), paddy land (21 samples), transportation land (12 samples), forestry land (15 samples), water surface land (9 samples), and unused land (12 samples). The results of the calculation comparing the satellite image interpretation and the control samples are the basis for evaluating accuracy of the study.

\subsubsection{Stakeholder and expert analysis}

To clarify the level of stakeholders' involvement in the process of implementing the research to propose land resource use and management solutions, the study determines the approaches for the cooperation and participation of stakeholders [23-24]. After collecting secondary data, a list of stakeholders is fully listed. Following the semi-structured interview method with staff, leaders involved in managing land use change. Next, potential stakeholders were identified, and then conducted semi-structured interviews of experts. A final list of stakeholders is used to classify. Based on the stakeholder power-interest matrix, the stakeholders were subsequently divided into four basic groups including Keep informed, Maintain interest, Active consultation, Key players. After classifying stakeholders, it is important to decide how to involve the stakeholders. Stakeholder analysis clarified the roles and functions and interactions between the parties. This method is significant in making the appropriate solutions recommendation [25-26]. In addition, to solidify the basis of proposing solutions for effective land for resource use management, the research conducted an expert interview based on the Likert scale [27]. Accordingly, the group of experts is explored and will evaluate the score of choosing the solutions based on professional knowledge and experience. Thus, the making solutions are proposed based on the methodological framework and is shown in Figure 3. 


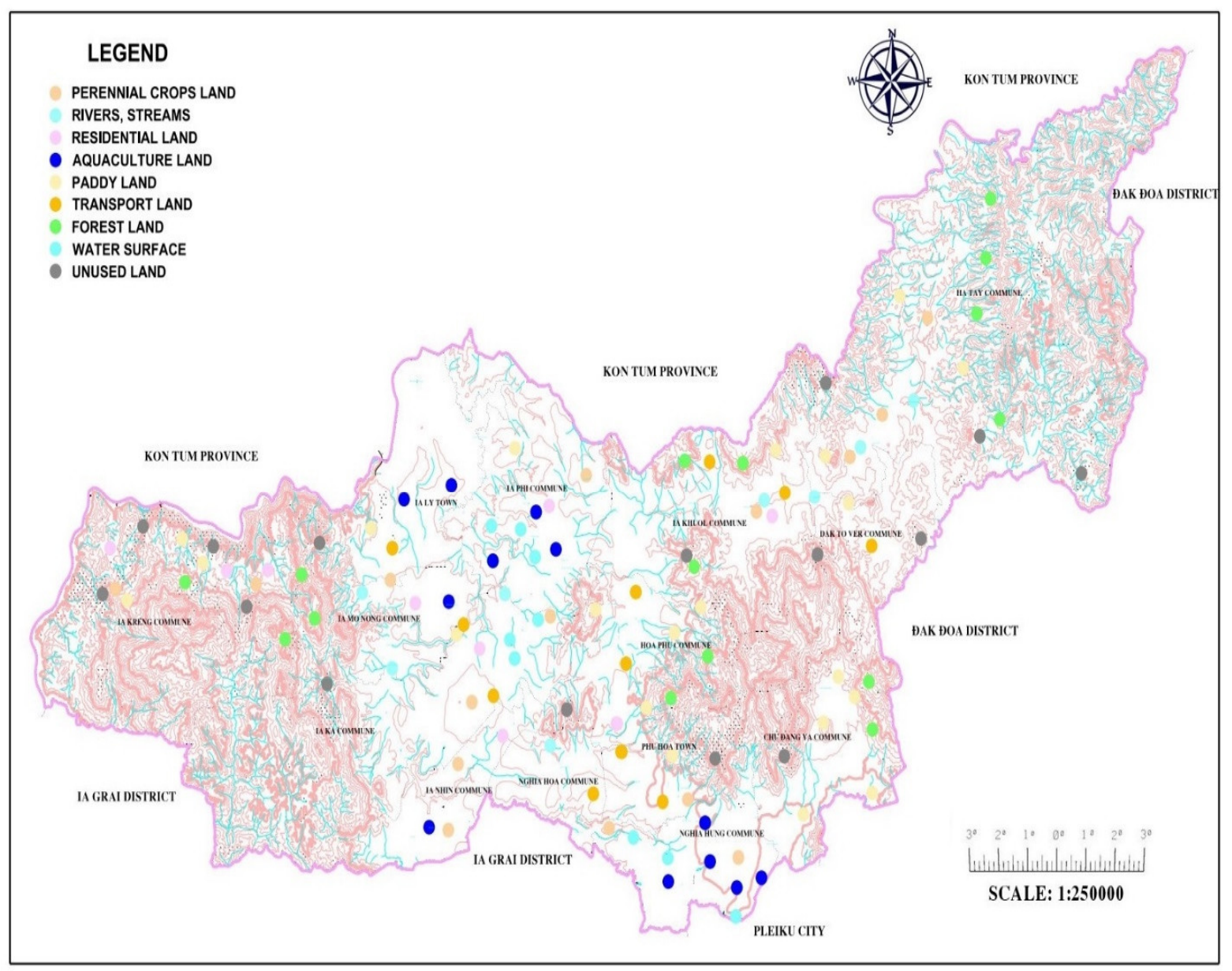

Figure 2. Map of field sampling to verify image classification.

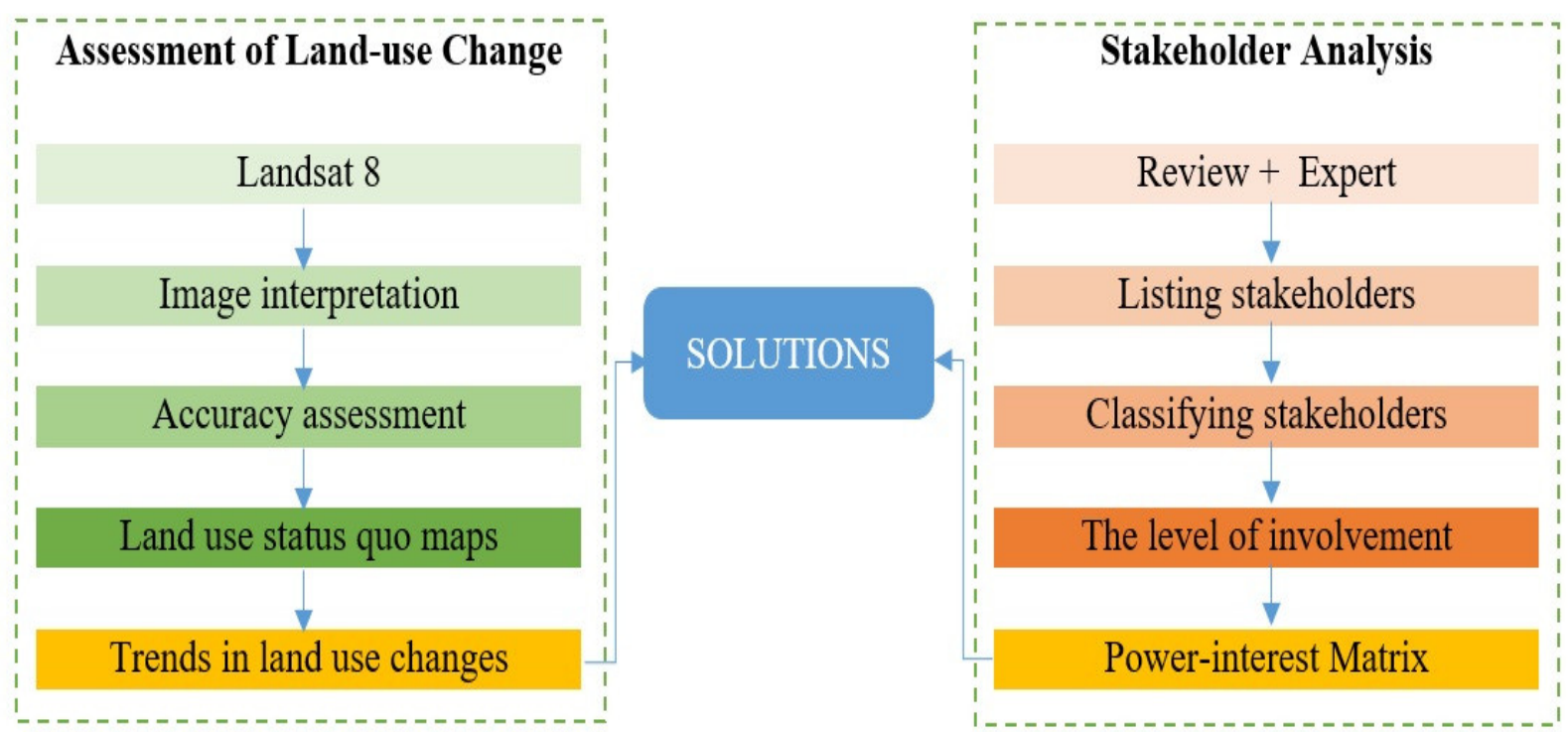

Figure 3. Methodological framework.

\subsubsection{Statistical method}

The data are calculated average (mean), standard deviation (SD) and analyzed using the softwares of M. Excel 2013 and SPSS V.13.0 for Windows. 


\section{Results and discussion}

\subsection{Land use change in Chu Pah district in the context of climate change}

\subsubsection{The current status of land use change}

The use of satellite imagery (ie., Landsat 5, 7 and 8) from Google Earth demonstrations the effective application in processing and assessing changes in land resources [7] by the spatial interpretation and analysis. In 2019, the area of natural land in Chu Pah district was 97,221.37 ha, lower than that in 2014 (97,457.68 ha) with the decline of 236.30 ha (Figures 5 and 6). The reason is due to the change of administrative boundaries between Gia Lai and Kon Tum provinces, which was determined according to Resolution No. 113/NQ-CP [28].

\subsubsection{Change of land use categories}

In 2019, the results illustrate that agriculture land was $86,160.44$ ha and witnessed an increase of 1,085.22 ha (an average rise of 217.04 ha/year, corresponding to the rate of $0.25 \%$ year) in the period 2014-2019 (Table 2). Obviously, the negative impact of climate change has caused difficulties for human activities such as the poor, vulnerable communities in rural areas $[18,29]$. This is a hug reason lead to change of land use in developing countries as Vietnam. The results found the highest increase is perennial crop land with 9,120.62 ha from annual crop land and unused land in the communes of Ha Tay, Ia Khuol, Ia Mo Nong and Ia Ka. In addition, the area of forest land increases 1,224.21 ha due to the area of planted forests in Ia Ly protection forest management unit (subdivision 215-Ia Kreng Commune) and Bien Ho protection forest management unit (subdivision 253-Hoa Phu commune). The current situation of rice land changes showed an increase of 329.30 ha due to the adjustment of paddy land along rivers and streams for the effective management and use of land resources in the communes of Ha Tay, Ia Khuol, and Ia Mo Nong. It can be seen that the assessment of the current state of changes in agricultural land resources plays an important role in proposing solutions to the effective management and use of local resources.

Table 2. Changes in agricultural land in the period 2014-2019.

\begin{tabular}{llcccc}
\hline \multirow{2}{*}{ ID } & Land use categories & \multicolumn{2}{c}{ Area (ha) } & \multirow{2}{*}{$\begin{array}{c}\text { Change } \\
\text { (ha) }\end{array}$} & $\begin{array}{c}\text { Rate } \\
\text { (\%)/year) }\end{array}$ \\
\cline { 3 - 4 } & Paddy land & $\mathbf{2 0 1 9}$ & $\mathbf{2 0 1 4}$ & & +1.41 \\
2 & Annual crop land & $13,440.22$ & $21,990.47$ & $-8,550.25$ & -12.72 \\
3 & Land for perennial crops & $38,339.22$ & $29,218.60$ & $+9,120.62$ & +4.76 \\
4 & Forest land & $29,541.67$ & $29,391.35$ & +150.32 & +0.04 \\
5 & Aquaculture land & 150.28 & 115.28 & +35.00 & -0.05 \\
6 & Other agricultural land & 31.10 & 30.85 & +0.25 & +4.66 \\
& $\quad$ Total & $86,160.44$ & $85,075.22$ & $+1,085.22$ & +0.25 \\
\hline
\end{tabular}

Figure 4 shows the fluctuation of non-agricultural land group in the period 2014-2019 in Chu Pah district. Notably, residential land increased by 22.44 ha, corresponding to an increase of $0.56 \%$ year due to the needs of infrastructure development in the context of rapid population growth. The results show similarities with previous studies on the causes of urban expansion in the Central Highlands [30]. 


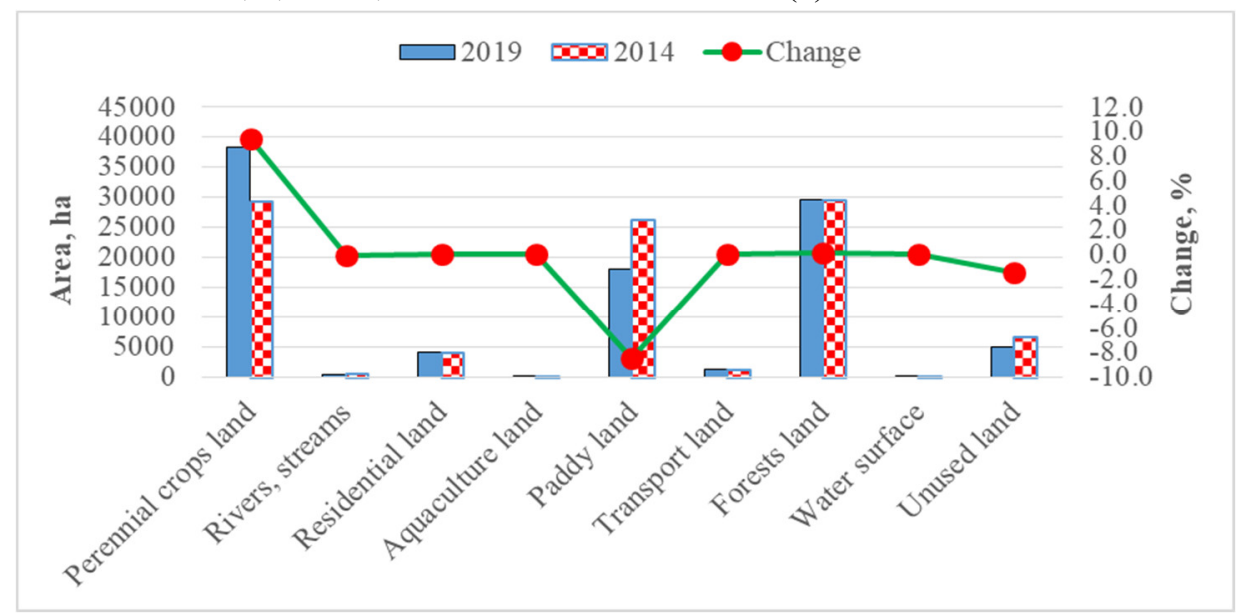

Figure 4. Changes in agricultural land in the period 2014-2019.

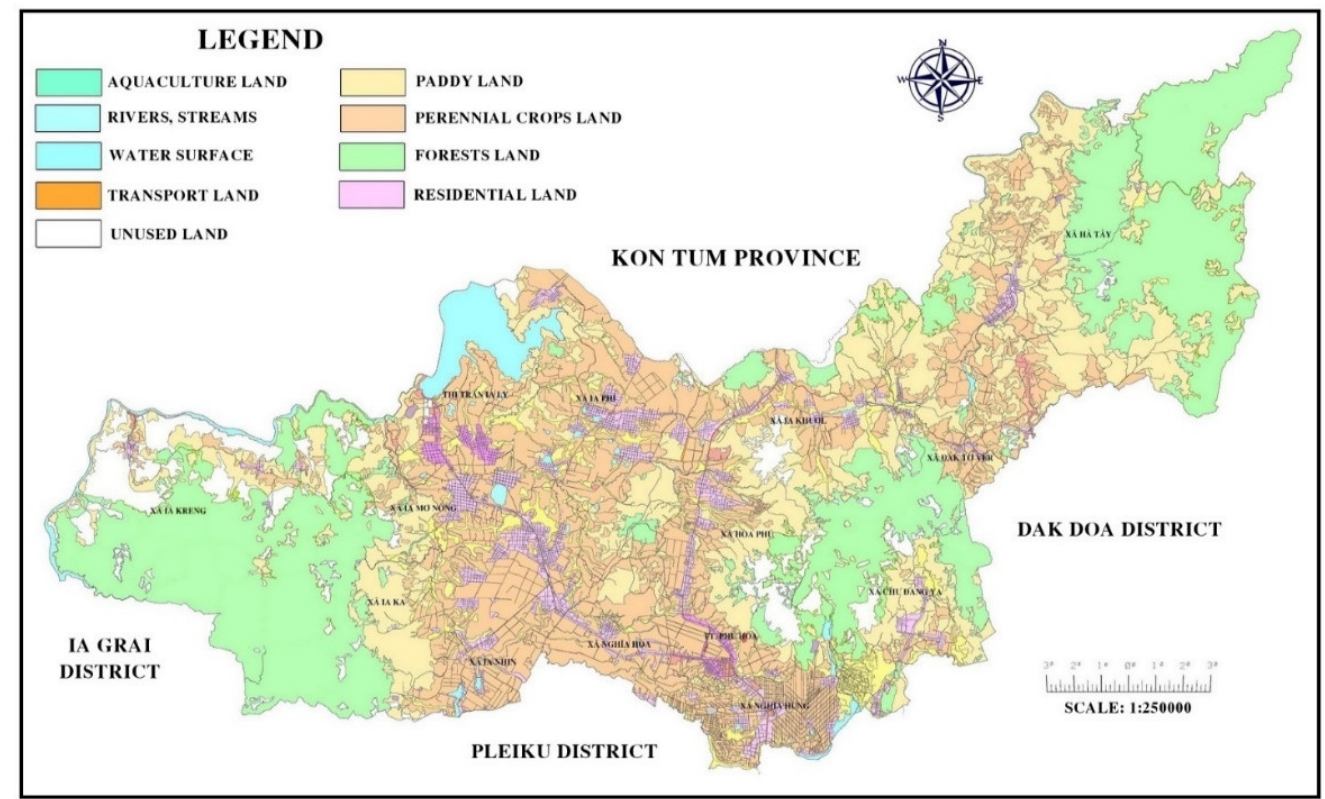

Figure 5. Current land use map in Chu Pah district in 2014.

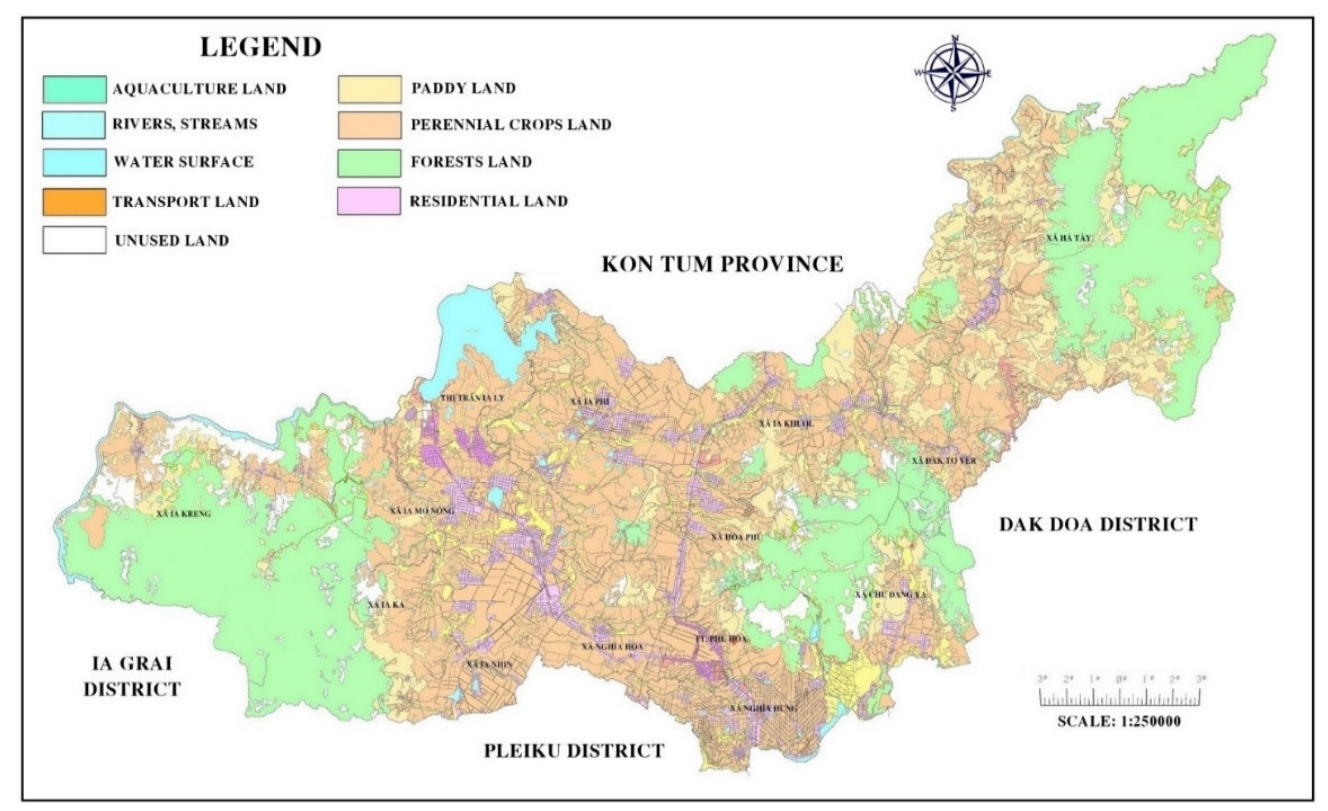

Figure 6. Current land use map in Chu Pah district in 2019. 


\subsubsection{Evaluate the reliability}

Evaluating the reliability of satellite imagery interpretation has an important role and confirmed the acceptability levels [30-31]. During random field sampling, matrix studies compute the accuracy level through Overall Accuracy and Kappa's index. Table 3 shows that the accuracy level in the image classification process is high with the lowest rate corresponding to $75.0 \%$ (for example: aquaculture land, unused land). In contrast, the groups such as residential land, transportation, rivers and streams have very high accuracy. Normally, the accuracy of over $75.0 \%$ Google Earth satellite image interpretation is satisfactory and acceptable. In this study, the Overall Accuracy was $87.8 \%$ and Kappa index was $86.3 \%$ represents high reliability. Thus, the results of the study showed that the Overall Accuracy in the process of creating land use maps of Chu Pah district and the Kappa index is acceptable. It can be seen that the imagery interpretation process to assess land use change in Chu Pah district is effective and meets the criteria of imagery classification.

Table 3. Matrix of accuracy evaluation after imagery classification.

\begin{tabular}{lcccccccccc}
\hline \multicolumn{10}{c}{ Field-proven by GPS } \\
\hline Land classify & $\begin{array}{l}\text { Perennial } \\
\text { crops } \\
\text { land }\end{array}$ & $\begin{array}{l}\text { Rivers, } \\
\text { streams }\end{array}$ & $\begin{array}{l}\text { Residen } \\
\text { tial land }\end{array}$ & $\begin{array}{l}\text { Aquacul } \\
\text { ture } \\
\text { land }\end{array}$ & $\begin{array}{l}\text { Paddy } \\
\text { land }\end{array}$ & $\begin{array}{l}\text { Trans } \\
\text { port } \\
\text { land }\end{array}$ & $\begin{array}{l}\text { Forest } \\
\text { land }\end{array}$ & $\begin{array}{l}\text { Water } \\
\text { surface land }\end{array}$ & Unused \\
Perennial crops \\
land & 12 & 0 & 0 & 0 & 3 & 0 & 0 & 0 & 0 & 15 \\
Rivers, streams & 0 & 9 & 0 & 0 & 0 & 0 & 0 & 0 & 0 & 9 \\
Residential land & 0 & 0 & 18 & 0 & 0 & 0 & 3 & 0 & 0 & 21 \\
Aquaculture land & 0 & 0 & 0 & 6 & 0 & 0 & 0 & 0 & 0 & 6 \\
Paddy land & 0 & 0 & 0 & 0 & 18 & 0 & 0 & 0 & 3 & 21 \\
Transport land & 0 & 0 & 0 & 0 & 0 & 12 & 0 & 0 & 0 & 12 \\
Forests land & 3 & 0 & 0 & 0 & 0 & 0 & 12 & 0 & 0 & 15 \\
Water surface & 0 & 0 & 0 & 3 & 0 & 0 & 0 & 9 & 0 & 12 \\
Unused land & 0 & 0 & 0 & 3 & 0 & 0 & 0 & 0 & 9 & 12 \\
Sum & 15 & 9 & 18 & 12 & 21 & 12 & 15 & 9 & 12 & 123 \\
\hline
\end{tabular}

\subsection{Analyze stakeholders and propose effective management solutions}

Stakeholder analysis is a useful tool based on a coordinated and supportive approach to sustainable land resource management [32-33]. In this study, the matrix would examines the interest and influence with 3 levels (low-medium-high), which are classified into 4 groups (Figure 7).

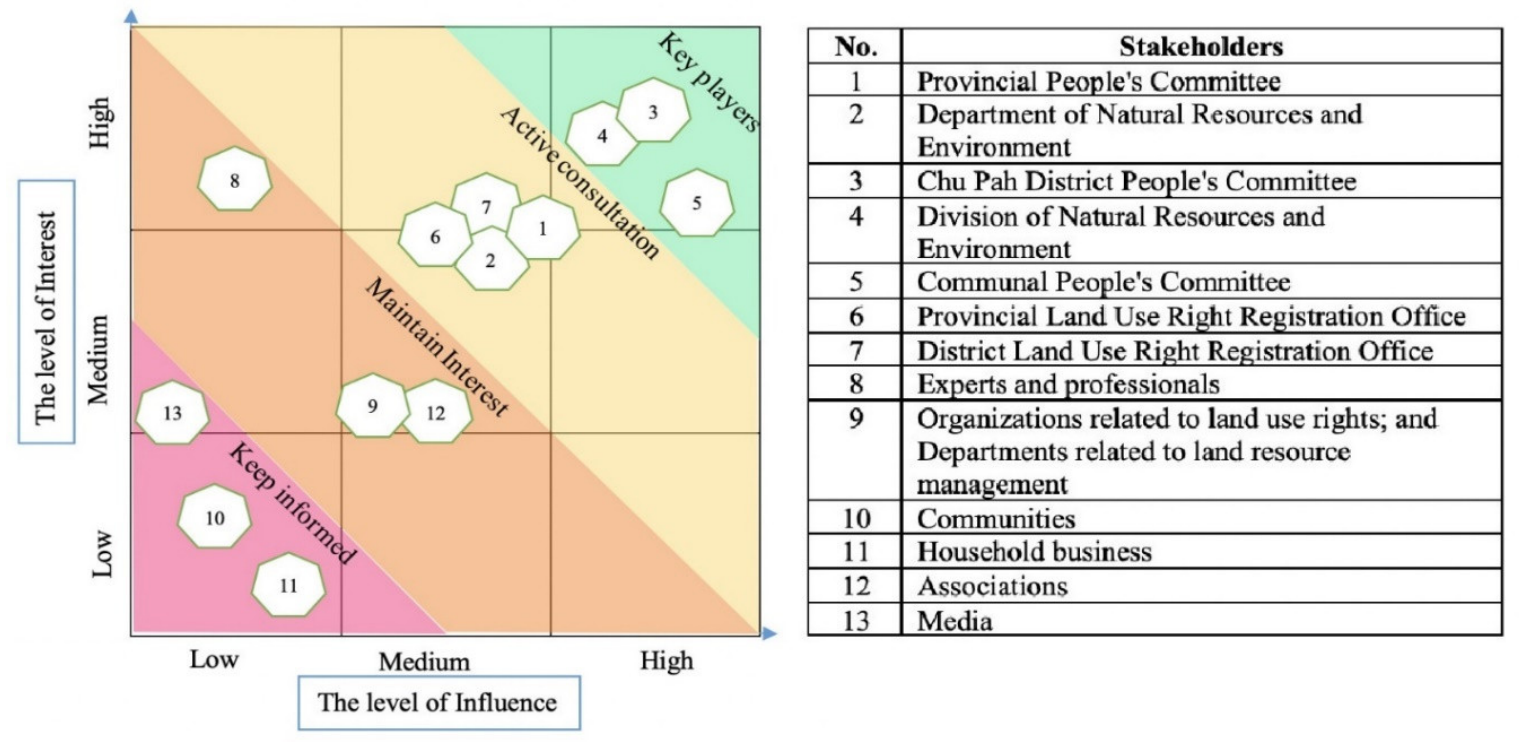

Figure 7. Matrix of stakeholder analysis. 
The process of analyzing stakeholders specifically classifies: (i) The group of key stakeholders that are direct participants (high level of importance and influence) includes: The Division of Natural Resources and Environment is a specialized agency to advise and assist the Chu Pah District People's Committee in performing the state management function in the field of natural resources and environment; At the commune level, cadastral and environmental officers are responsible for advising and performing tasks to assist the communal People's Committee to organize the implementation in the fields of land use management, environmental resources, construction, urban, transport, agriculture; (ii) A group of stakeholders that requires proactive consultation (medium to high impact and low to moderate interest) including the Department of Natural Resources and Environment to advise and assist the Provincial People's Committee and coordinating with the Land Use Right Registration Office at the provincial and district level); (iii) A group of stakeholders that need to maintain an interest (medium to high level of interest, low influence) including experts and professionals (consultants, expert advisors, policy); organizations related to land use rights; and departments related to land resource management; (iv) A group of stakeholders who should exchange information (low interest and low influence) including residential communities, household business, and media.

On the other hand, based on the current situation as well as the analysis and grouping of stakeholders, combine with expert survey in the context of climate change, the study proposed some solutions for effective land use resource management in Chu Pah according to the priority categories.

Table 4. Proposal on solutions for efficient management and use of land resources.

\begin{tabular}{|c|c|c|c|}
\hline Code & Recommended solution & Values $^{1}$ & Ranking \\
\hline $\mathrm{GP}_{1}$ & $\begin{array}{l}\text { Develop and implement programs to support sustainable } \\
\text { livelihoods, stabilize life and economic development. }\end{array}$ & $4.724 \pm 0.578$ & I \\
\hline $\mathrm{GP}_{2}$ & $\begin{array}{l}\text { Strengthen inspection and supervision of the use of land } \\
\text { resources; strictly handle violations of approved land use } \\
\text { plannings. }\end{array}$ & $4.451 \pm 0.285$ & II \\
\hline $\mathrm{GP}_{3}$ & $\begin{array}{l}\text { Investment in the documents for land resource management } \\
\text { such as cadastral mapping, certificate of land use rights. }\end{array}$ & $4.037 \pm 0.963$ & III \\
\hline $\mathrm{GP}_{4}$ & $\begin{array}{l}\text { Policy of improving unused land resources, improving the } \\
\text { efficiency of agricultural and forestry land exploitation to } \\
\text { meet development needs in the sustainability and protection } \\
\text { of the ecological environment. }\end{array}$ & $3.831 \pm 0.321$ & IV \\
\hline
\end{tabular}

Notes: GP ${ }_{1-4}$ : Solutions from 1 to $4 .{ }^{1}$ Values: Mean $\pm S D$ of 5-point Likert scale.

In general, strengthening sustainable land use management should be aimed at using land ecology efficiently [34], thereby contributing to reducing the global consequences in the exploitation and use of land resources [35]. Survey results with priority order: developing and implementing a sustainable livelihood support program $>$ monitoring the implementation of land use $>$ developing documents for resource land management resource $>$ improving unused land resources and the efficiency of agricultural land exploitation. In which, the average value of the expert assessment is to build and implement the sustainable livelihood support program $\left(\mathrm{GP}_{1}\right)$ with the highest result of $4.724(\mathrm{SD}=0.578)$. Similarly, the solutions of $\mathrm{GP}_{2}, \mathrm{GP}_{3}, \mathrm{GP}_{4}$ with the average values are $4.451(\mathrm{SD}=0.285) ; 4.037(\mathrm{SD}=0.963)$ and $3.831(\mathrm{SD}=0.321)$ respectively. Therefore, it is recommended to pay attention to solutions to improve the efficiency of agricultural and forestry land exploitation in order to meet the needs of sustainable development and protection of the ecological environment.

\section{Conclusions}

The results of applying Google Earth satellite imagery interpretation approach to establish land use maps help illustrate the distribution of land-use space in Chu Pah district. The Overall Accuracy and Kappa index were respectively $87.8 \%$ and $86.3 \%$, representing 
high reliability. From our study of the land use changes in Chu Pah district showed that the conversion from annual crop land into perennial crop land was outstanding in the period 2014-2019. Analysis of the use of non-agricultural land groups can be seen that the residential land area has increased significantly (22.44 ha) to serve the needs of transforming economic development and responding to population growth. In addition, the negative impact of climate change can be caused change of land use in developing countries. The negative impact of climate change has been caused difficulties for human as well as agricultural activities in Chu Pah district. The results also found that the cooperation and participation of stakeholders is the foundation for effective management of land resources use on the basis of accountability and coordination. In order to limit the situation of self-conversion of land use categories not according to planning the specialized agency should consider relevant recommendations. However, limitations of the current study can be existed by the pixels in the affected highland areas, which cannot be detected as well as other zones (e.g. plain areas). The difference between this study and land inventory status quo might be occurred in the small scope. In the future, we should be used the higher-resolution images to investigate these changes.

Acknowledgments: The authors would like to thank the Chu Pah District People's Committee, Chu Pah Department of Natural Resources and Environment for research funding and providing key information for this study.

Author contributions: Constructing research ideas: N.N.H., N.T.A.; Select research method: N.T.A., N.N.H., N.M.K.; Survey, sampling and analysis: N.N.H., N.T.A., N.M.K., N.H.D.M., N.T.L., N.T.N.H.; Data processing: N.N.H., N.T.A., N.M.K., B.Q.D.; Writingoriginal draft preparation: N.N.H., N.T.A., N.M.K.; Writing-review and editing: N.N.H., N.T.A., N.M.K., B.Q.D.

Conflicts of Interest: The authors declare no conflict of interest.

\section{References}

1. Chauhan, H.; Nayak, S. Land Use/Land Cover Changes near Hazira Region, Gujarat Using Remote Sensing Satellite Data. J. Indian Soc. Remote Sens. 2005, 33, 413420.

2. Ky, N.M.; Thuong, N.T.L.; Phu, B.K.; Dang, T.L.H. Remote Sensing and GIS Technology Application to Assess a Forest Resources Fluctuation in ChuProng District, Gia Lai Province. An Giang Uni. J. Sci. 2019, 22, 67-80.

3. LaGro, J.A.; DeGloria, S.D. Land Use Dynamics within an Urbanizing NonMetropolitan County in New York State (USA). Landsc. Ecol. 1992, 7, 275-289.

4. Andersen, L.E. The Causes of Deforestation in the Brazilian Amazon. J. Environ. Dev. 1996, 5, 309-328.

5. Mallupattu, P.K.; Sreenivasula Reddy, J.R. Analysis of Land Use/Land Cover Changes Using Remote Sensing Data and GIS at an Urban Area, Tirupati, India. Sci. World J. 2013, 2013, pp. 6. https://doi.org/10.1155/2013/268623.

6. Mertens, B.; Lambin, E.F. Spatial Modelling of Deforestation in Southern Cameroon: Spatial Disaggregation of Diverse Deforestation Processes. Appl. Geogr. 1997, 17, 143-162.

7. Huang, H.; Chen, Y.; Clinton, N.; Wang, J.; Wang, X.; Liu, C.; Gong, P.; Yang, J.; Bai, Y.; Zheng, Y. Mapping Major Land Cover Dynamics in Beijing Using All Landsat Images in Google Earth Engine. Remote Sens. Environ. 2017, 202, 166-176.

8. Jacobson, A.; Dhanota, J.; Godfrey, J.; Jacobson, H.; Rossman, Z.; Stanish, A.; Walker, H.; Riggio, J. A Novel Approach to Mapping Land Conversion Using Google Earth with an Application to East Africa. Environ. Model. Softw. 2015, 72, 1-9. 
9. Malarvizhi, K.; Kumar, S. V.; Porchelvan, P. Use of High Resolution Google Earth Satellite Imagery in Landuse Map Preparation for Urban Related Applications. Proc. Technol. 2016, 24, 1835-1842.

10. Munroe, D.K.; Müller, D. Issues in Spatially Explicit Statistical Land-Use/Cover Change (LUCC) Models: Examples from Western Honduras and the Central Highlands of Vietnam. Land Use Policy 2007, 24, 521-530.

11. GL. PPC. Resolution No. 100/NQ-HDND dated 7/12/2017 on Approving the Results of Reviewing and Adjusting the Planning of 3 Forest Types to 2025 and a Vision to 2030 in Gia Lai Province. Gia Lai Provincial People's Committee: Gia Lai, 2017.

12. MONRE. National State of the Environment Report 2016: Urban Environment; Vietnam Publishing House of Natural Resources, Environment and Cartographic, 2017.

13. MONRE. Climate Change, Sea Level Rise Scenarios for Vietnam. Publisher of Map and Environment Resources: Hanoi, 2012.

14. Akpoti, K.; Antwi, E.O.; Kabo-bah, A.T. Impacts of Rainfall Variability, Land Use and Land Cover Change on Stream Flow of the Black Volta Basin, West Africa. $J$. Hydrol. 2016, 3, 26.

15. Chakilu, G.; Moges, M. Assessing the Land Use/Cover Dynamics and Its Impact on the Low Flow of Gumara Watershed, Upper Blue Nile Basin, Ethiopia. Hydrol. Current Res. 2017, 7, 268.

16. Hang, L.T.; Hung, N.T.Q.; Ky, N.M. Impacts of climate change and public awareness of coffee production activities in Gia Lai province. J. Agric. Rural Dev. 2017, 20, 21-28.

17. Khoa, N.P. Developing Climate Change Response Map for the Agricultural Sector of Gia Lai Province in 2013, with an Orientation to 2020 and a Vision to 2030. HueUni-JARD, 2015, 108 (9). https://doi.org/10.26459/jard.v108i9.2923.

18. CP.DPC. Report on Land Inventory Results and Land Use Status Quo Map in 2019 - Chu Pah District. Chu Pah District People's Committee, 2020.

19. MONRE. Using the coordinate transformation between world geodetic system WGS84 and national geodetic system VN2000. Ministry of Environment and Resources: Hanoi, 2007.

20. Mohammed, N.Z.; Ghazi, A.; Mustafa, H.E. Positional Accuracy Testing of Google Earth. IJMSE 2013, 4, 6-9.

21. Tilahun, A.; Teferie, B. Accuracy Assessment of Land Use Land Cover Classification Using Google Earth. Am. J. Environ. Prot. 2015, 4, 193-198.

22. Congalton, R.G. A Review of Assessing the Accuracy of Classifications of Remotely Sensed Data. Remote Sens. Environ. 1991, 37, 35-46.

23. Brown, G.; de Bie, K.; Weber, D. Identifying Public Land Stakeholder Perspectives for Implementing Place-Based Land Management. Landsc Urban Plan. 2015, 139, $1-15$.

24. Reed, M.S.; Graves, A.; Dandy, N.; Posthumus, H.; Hubacek, K.; Morris, J.; Prell, C.; Quinn, C.H.; Stringer, L.C. Who's in and Why? A Typology of Stakeholder Analysis Methods for Natural Resource Management. J. Environ. Manage. 2009, 90, 1933-1949.

25. Anh, N.T.; Hai, N.N.; Trang, T.T.T; Dung, B.Q.; Ky, N.M. Analyzing Stakeholder Involvement in Urban Domestic Water Supply System - Case Study in Central Highland of Vietnam. $V N$ J. Hydrometeorol. 2019, 2-1, 56-65. https://doi.org/10.36335/VNJHM.2019(2-1).56-65.

26. Bryson, J.M. What to Do When Stakeholders Matter: Stakeholder Identification and Analysis Techniques. Public Manag. Rev. 2004, 6, 21-53. 
27. Joshi, A.; Kale, S.; Chandel, S.; Pal, D.K. Likert Scale: Explored and Explained. Curr. J. Appl. Sci. Technol. 2015, 7, 396-403.

28. Vietnamese Government. Resolution No. 113/NQ-CP dated December 5, 2019 on the Determination of the Administrative Boundaries between Kon Tum and Gia Lai Provinces in Three Historical Regions, Hanoi, 2019.

29. Thang, L.V.; Ky, N.M. Assessing the study of climate change trend in Vietnam: A case study in Danang City. HUJOS - Earth Sci. Environ. 2017, 126, 19-28.

30. Hai, N.N.; Anh, N.T.; Khuong, T.N.L.; Dung, B.Q.; Ky, N.M. Research on Urban Sprawl Trends and Landscape Change in Pleiku City, Gia Lai Province. VN J. Hydrometeorol. 2019, 2-1, 37-47. https://doi.org/10.36335/VNJHM.2019(2-1).3747.

31. Tilahun, A.; Teferie, B. Accuracy Assessment of Land Use Land Cover Classification Using Google Earth. Am. J. Environ. Prot. 2015, 4, 193-198.

32. Schwilch, G.; Bachmann, F.; Valente, S.; Coelho, C.; Moreira, J.; Laouina, A.; Chaker, M.; Aderghal, M.; Santos, P.; Reed, M.S. A Structured Multi-Stakeholder Learning Process for Sustainable Land Management. J. Environ. Manage. 2012, 107, $52-63$.

33. Wang, J.; Aenis, T. Stakeholder Analysis in Support of Sustainable Land Management: Experiences from Southwest China. J. Environ. Manage. 2019, 243, $1-11$.

34. Deng, X.; Gibson, J. Sustainable Land Use Management for Improving Land EcoEfficiency: A Case Study of Hebei, China. Ann. Oper. Res. 2020, 290, 265-277.

35. Foley, J.A.; DeFries, R.; Asner, G.P.; Barford, C.; Bonan, G.; Carpenter, S.R.; Chapin, F.S.; Coe, M.T.; Daily, G.C.; Gibbs, H.K. Global Consequences of Land Use. Sci. 2005, 309, 570-574. 